\title{
Coronavirus Disease-19 Pandemic and Dermatology. What to Expect?
}

\author{
Vesna Brishkoska-Boshkovski ${ }^{1}$, Mirela Vasileva ${ }^{2}$, Irena Dimitrovska ${ }^{1}$, Vesna Grivcheva-Panovska ${ }^{3}$ \\ ${ }^{1}$ Department of Dermatology, General Hospital " 8 th September", Skopje, Republic of Macedonia; ${ }^{2}$ Department of Dermatology, Clinical \\ Hospital, Shtip, Macedonia; ${ }^{3}$ University Clinic of Dermatology, University Sts Cyril and Methodius, Skopje, Republic of Macedonia
}

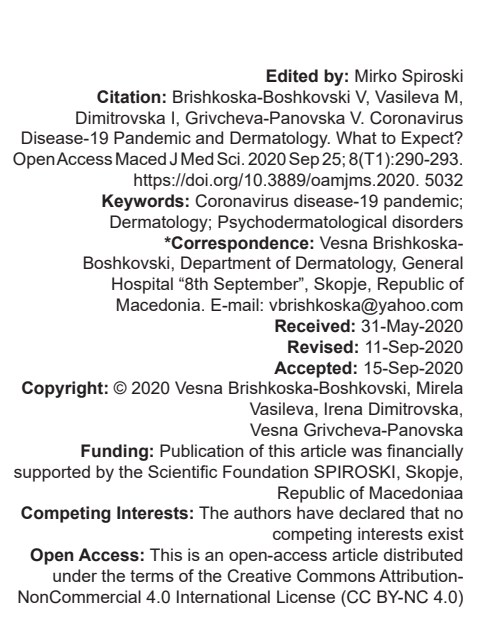

\section{Introduction}

The coronavirus (CoV) disease (COVID)-19 pandemic, or COVID-2019, is caused by several acute respiratory syndrome CoV-2. On January 12, 2020, the World Health Organization (WHO) confirmed that a novel CoV was the cause of a respiratory illness in a cluster of people in Wuhan City, Hubei Province China. The WHO declared the outbreak a public health emergency of international concern on January 30, and a pandemic on March 11. On the end of May almost 6 million cases of COVID-19 have been reported in more than 230 countries, resulting in more than 370,000 deaths.

The novel CoV, COVID-19, and ongoing pandemic, is changing every aspect of human life. Furthermore, COVID-19 pandemic has a profound impact on health-care worldwide, with no exception in dermatology care units. The dermatological practices are affected, although with much OR less extensity than the emergency and intensive care departments which are working with the suspected and confirmed COVID-19 patients. Chen et al. reported the impact on dermatology outpatient care at the outbreak epicenter in Wuhan,
China [1]. To meet the medical requirements and reduce the flow of patients to the dermatology departments, the measures which were taken by the public hospitals and private practices are dramatically reduction in outpatient consultations. In order to care for the patients safely and effectively, dermatological practices converted the face-to-face examination to telephone and online consultations. Esthetic dermatological procedures, laser sessions, have been stopped, almost completely. Only patients with dermatologic emergencies and acute skin failures are admitted in hospitals. In an era of quarantine and isolation, dermatologists utilize teledermatology better than other specialties. Communication modes can be video, audio, and text based - Viber, WhatsApp, and Facebook messenger, are the virtual tools being used for teledermatology practices. The advantages using teledermatology are: Permits consultation without increased risk of infection, very important is cost-effective, and provides accurate diagnostic information [2]. The key aspect of risk management in the dermatology practices is prevention of COVID-19 in population at risk, and that is the patient with chronic inflammatory skin disease, patients on immunosuppressive, and biologics therapy. British Association of Dermatologists (BAD) provided guidelines for high risk patients on immunosuppressive medications or biologics/ 
Monoclonal (anti-tumor necrosis factor drugs, Interleukin (IL) 17 agents, anti-B cell, IL-6 agents, and IL-1) or novel molecule immunosuppressant (apremilast, JAK inhibitors) and patients on corticosteroid dose of $\geq 20$ $\mathrm{mg}$ of prednisolone/daily for more than 4 weeks; to undergo with self-isolation up to 12 weeks. Patients treated with single immunosuppressant or biologics and no comorbidities, stressed the need to maintain social distancing [3]. BAD advises using teledermatology and avoiding hospital visits as much as possible [4]. American Academy of Dermatology and international Psoriasis council also suggest recommendations on using the biologics and immunosuppressant in COVID-19 positive patients [5], [6]. Guidelines for dermatoscopy during COVID-19 pandemic have been also suggested [7].

\section{COVID-19 Pandemic and Psychodermatological Disorders. What to Expect?}

At the time of COVID-19 pandemic, constant fear and stress are present on the surface. During a pandemic and restricted movement, the constant need to wear face masks, adhere to the rules of keeping a social distance of $2 \mathrm{~m}$, constantly washing hands, and continuously media accentuating about the danger of the virus and infection led to milder or more severe mental problems. Skin diseases are the most common somatic causes of psychological disorders and, conversely. During a stressful situation, the body has the power to adjust to maintain its well-being, but with prolonged exposure to stress, the first negative changes such as fear, anxiety, and depression will eventually lead to chronic fatigue and an increased risk of disease. In this paper, we will look at the most common psychodermatological disorders and its implication in the era of COVID-19 pandemic.

Dermatological conditions are closely related to stress. Stress is a trigger factor for a lot of cutaneous diseases: Alopecia areata, psoriasis, vitiligo, lichen planus, acne, atopic dermatitis, and urticaria. What matter is the "perceived stress," or patient's perception of the stressful situation, which sometimes its greater than the stress itself. This perception is usually influenced by the psychological state of the patient. Anxiety, depression could change the perception of the event [8].

The exact prevalence of psychological factors that affect skin disease is not known; however, it has been estimated to be $25-33 \%$ in various studies [8]. Brain, nerves, and skin are embryologically derived from the neural plate in the ectoderm. The neuroimmuno-cutaneous-endocrine model was proposed by O'Sullivan et al., to explain the relationship of the body and mind [9].
The role of the neuropeptides, hormones, and neurotransmitters in the pathogenesis of psychotic diseases is subject of research by a number of scientists. Stress is known to activate the two major neural pathways, the first is the hypothalamic-pituitaryadrenal axis and the second is the sympathetic nervous system. Stress triggers the secretion of adrenal glucocorticosteroids and catecholamines, the secreted amount of which, will act as a negative feedback on the secretion of corticotropin-releasing hormone, which stimulates the sympathetic nervous system and the secretion of epinephrine and norepinephrine [8].

Catecholamines and corticosteroids have an inhibitory effect on the immune system, reduce the secretion of IL-2 and IL-8, affect the differentiation of $T$ cells, and activate cellular immunity. From the terminal nerve endings in the skin begin to release neuropeptides such as calcitonin gene released peptide and substance $P$, which are the main culprits for the existence of psychosomatic skin diseases. As a result of these reactions, the body's allergic and inflammatory responses increase [8]. Psychological stress has a negative influence on barrier function of the skin and its antimicrobial defense, both by glucocorticoiddependent mechanism [10].

Although there is no single universally accepted classification system of psychocutaneous disorders and many of the conditions are overlapped into different categories, the most widely accepted system is that devised by Koo and Lee [11]. In psychophysiological psychocutaneous disorders, the skin disease is not caused by stress but appears to be precipitated or exacerbated by the stress [11]. The proportion of patients reporting emotional triggers varies with the disease, ranging from approximately $50 \%$ in acne to $90 \%$ in rosacea, alopecia areata, neurotic excoriations, and lichen simplex and may be $100 \%$ for patients with hyperhidrosis [11]. Onset or exacerbation of psoriasis can be triggers by a number of common stressors. Stress has been reported in $44 \%$ of patients before the initial flare of psoriasis, and recurrent flares have been attributed to stress in up to $80 \%$ of individuals [12]. In a study analyzing, the stressful situations described in psoriatic patients the most common were death of a family member, own disease or serious disease of a family member [13]. Stressful life events precede the onset of disease in more than $70 \%$ of atopic dermatitis patients [14]. A case-control study of Willemsen et al. reported higher score and impact of lifetime and childhood traumatic events, in alopecia areata adults [15]. There are reports that alopecia areata pediatric patients experienced more stressful events [16]. Stressful events precede the onset of lesions in vitiligo patients, compared to controls [17]. Severe emotional stress may exacerbate pre-existing urticaria. Increased emotional tension, fatigue, and stressful life situations may be primary factors in more than $20 \%$ of cases and are contributory in $68 \%$ of these 
patients [11]. There is increasing evidence that stress has a role in recurrent herpetic infection [18]. Several psychological stress of any sort, may depress cellmediated immune response, predisposing children to the Herpes zoster virus [19].

Such evidence raises the possibility that the psychosocial stress induced by the COVID-19 pandemic can potentially lead to exacerbations or onset of common inflammatory skin conditions (e.g., psoriasis, atopic eczema, urticaria, and pruritic conditions), both in the short term and after the resolution of the pandemic [20]. Soon, we will have to deal with short- and long-term psychosocial effects related to the COVID-19 pandemic on patients with dermatological disorders, and we encourage comprehensive studies of the implications of the COVID-19 pandemic in these patients.

\section{Conclusion}

As COVID-19 pandemic rapidly spreads across the world, it is inducing a considerable degree of fear, worry and stress, for many individuals, arising from the disease itself, and from measures such as social and physical distancing. In public mental health terms, the main psychological impact to date is elevated rates of stress or anxiety. However, as new measures and impacts are introduced, especially quarantine and its effects on many people's usual activities, routines or livelihoods - levels of loneliness, depression, using drugs, alcohol, and self-harm or suicidal behavior are also expected to rise.

Stressful events could induce a psychosomatic disease, especially in some patients with high reactivity to stress. We will be witnessing a growing number in patient consultations with chronic urticaria, dermographism, worsening rosacea, seborrheic dermatitis, generalization, and relapses of psoriasis and alopecia. Mental stress can influence the disease, causing flare-ups and being the main triggering factor. Stress suggests a poor prognosis. In general, there is a need for improved coordination of primary healthcare, dermatovenereologists and psychiatric, and psychological services in the health system. It is needed to be prepared for as many cases as possible, because the psychological consequences will still be felt.

\section{References}

1. Chen Y, Pradhan S, Xue S. What are we doing in the dermatology outpatient department amidst the raging of the 2019 novel coronavirus? J Am Acad Dermatol. 2020;82(4):1034. https://doi. org/10.1016/j.jaad.2020.02.030

\section{PMid:32081700}

2. Warshaw EM, Hillman YJ, Greer NL, Hagel EM, MacDonald R, Rutks IR, et al. Teledermatology for diagnosis and management of skin conditions: A systematicreview. J Am Acad Dermatol. 2011;64(4):759-72.

PMid:21036419

3. Dermatology Advice Regarding Self-isolation and Immunosuppressed Patients: Adults, Paediatrics and Young People. Healthcare Professionals. British Association of Dermatologists. Available from: https://www. badorguk/healthcare-professionals/covid-19/covid-19immunosuppressed-patients. [Last accessed on 2020 Apr 14].

4. COVID-19: Clinical Guidelines for the Management of Dermatology Patients Remotely. Healthcare Professionals British Association of Dermatologists. Available from: https:// www.badorguk/healthcare-professionals/covid-19/remotedermatology-guidance. [Last accessed on 2020 Jun 17].

5. Price KN, Frew JW, Hsiao JL, Shi VY. COVID19 and immunomodulator/immunosuppressant use in dermatology. J Am Acad Dermatol. 2020;82:e173-5.

PMid:32224277

6. Statement on the Coronavirus (COVID-19) Outbreak International Psoriasis Council; 2020. Available from: http:// www.psoriasiscouncil.org. [Last accessed on 2020 Sep 1]

7. Jakhar D, Kaur I, Kaul S. Art of performing dermoscopy during the times of coronavirus disease (COVID-19): Simple change in approach can save the day? J Eur Acad Dermatol Venereol. 2020;34(6):e242-4. https://doi.org/10.1111/jdv.16412 PMid:32223004

8. Eva MJ. Stressed skin? A molecular psychosomatic update on stress-causes and effects in dermatologic diseases. J Dtsch Dermatol Ges. 2016;14(3):233-52. https://doi.org/10.1111/ ddg. 12957

PMid:26972185

9. O'Sullivan RL, Lipper G, Lerner EA. The neuro-immunocutaneous-endocrine network: Relationship of mind and skin. Arch Dermatol. 1998;134(11):1431-5. https://doi.org/10.1001/ archderm.134.11.1431 PMid:9828880

10. Martin-Ezquerra G, Man MQ, Hupe $M$, Rodriguez-Martin $M$, Youm JK, Trullas C, et al. Psychological stress regulates antimicrobial peptide expression by both glucocorticoid and $\beta$-adrenergic mechanisms. Eur J Dermatol. 2011;21(2):48-51. https://doi.org/10.1684/ejd.2011.1273 PMid:21628130

11. Koo JY, Lee CS. General approach to evaluating psychodermatological disorders. In: Psychocutaneous Medicine. New York: Marcel Dekker, Inc.; 2003. p. 1-29.

12. Griffiths CE, Richards HL. Psychological influences in psoriasis. Clin Exp Dermatol. 2001;26(4):338-42. https://doi. org/10.1046/j.1365-2230.2001.00834.x

PMid:11422186

13. Arslanagić N, Arslanagić R. Effect of psychological trauma caused by war on manifestations of psoriasis. Med Arh. 2003;57(3):145-7.

PMid:12858652

14. Faulstich ME, Williamson DA, Duchmann EG, Conerly SL, Brantley PJ. Psychophysiological analysis of atopic dermatitis. J Psychosom Res. 1985;29(4):415-7. https://doi. org/10.1016/0022-3999(85)90027-3 PMid:4057129

15. Willemsen R, Vanderlinden $\mathrm{J}$, Roseeuw D, Haentjens $\mathrm{P}$. Increased history of childhood and lifetime traumatic events among adults with alopecia areata. J Am Acad Dermatol. 2009;60(3):388-93. https://doi.org/10.1016/j.jaad.2008.09.049 
PMid:19026463

16. Díaz-Atienza F, Gurpegui M. Environmental stress but not subjective distress in children or adolescents with alopecia areata. J Psychosom Res. 2011;71(2):102-7. https://doi. org/10.1016/j.jpsychores.2011.01.007

\section{PMid:21767691}

17. Prćić S, Durović D, Duran V, Vuković D, Gajinov Z. Some psychological characteristics of children and adolescents with vitiligo--our results. Med Pregl. 2006;59(5-6):265-9. https://doi. org/10.2298/mpns0606265p

PMid:17039911

18. Buske-Kirschbaum A, Geiben A, Wermke C, Pirke KM, Hellhammer D. Preliminary evidence for herpes labialis recurrence following experimentally induced disgust Psychother Psychosom. 2001;70(2):86-91. https://doi. org/10.1159/000056231

PMid:11244389

19. Gupta MA, Gupta AK. Herpes zoster in the medically healthy child and covert severe child abuse. Cutis. 2000;66(3):221-3.

PMid:11006859

20. Garcovich S, Bersani F, Chiricozzi A, De Simone C. Mass quarantine measures in the time of COVID-19 pandemic: Psychosocial implications for chronic skin conditions and a call for qualitative studies. J Eur Acad Dermatol Venereol. 2020;34(7):e293-4. https://doi.org/10.1111/jdv.16535

PMid:32330329 